\title{
Beta 3 Adrenoreceptor Agonist for the Management of Lower Urinary Tract Symptoms in Men With Benign Prostatic Hyperplasia: A Systematic Review
}

\author{
Tae Wook Kang ${ }^{1}$, Su Jin Kim ${ }^{1, \star}$, Myung Ha Kim², Jae Hung Jung ${ }^{1,3}$ \\ ${ }^{1}$ Department of Urology, Yonsei University Wonju College of Medicine, Wonju, Korea \\ ${ }^{2}$ Yonsei Wonju Medical Library, Yonsei University Wonju College of Medicine, Wonju, Korea \\ ${ }^{3}$ Center of Evidence Based Medicine, Institute of Convergence Science, Yonsei University, Seoul, Korea
}

Beta-3 adrenoceptor (B3AR) agonist which mediate detrusor relaxation has been tried as a new treatment modality for men with benign prostatic hyperplasia (BPH). However, it remains unclear whether the B3AR agonist has more clinical benefits and fewer adverse effects in men with BPH than in women. We performed a comprehensive search using multiple databases, trials registries, other sources of grey literature, and conference proceedings regardless of language or publication status and included randomized controlled trials. Two review authors independently screened the literature, extracted data, and assessed risk of bias. We performed statistical analyses using a random-effects model and interpreted them according to the Cochrane Handbook for Systematic Reviews of Interventions. Primary outcomes were urologic symptom scores, quality of life (QoL), and overall adverse events. We found 4 randomized controlled trials with 1,105 participants in 3 comparisons. All studies reported short-term outcomes (ranged from 8 weeks to 12 weeks). Mirabegron, tamsulosin, silodosin, fesoterodine, and tadalafil were administrated as intervention. While B3AR agonist can improve the patient-important outcomes within group (before and after treatment), B3AR agonist combination therapy with current standard BPH treatment such as alpha blocker or anticholinergic may not have additional effects on urological symptom scores and QoL compared to alpha blocker or anticholinergic monotherapy. B3AR agonist therapy with phosphodiesterase 5 inhibitor (PDE5I) showed statistical improvement on urological symptom scores or QoL compared to PDE5I monotherapy. For safety profile, B3AR agonist in all 3 comparisons may not increase adverse event rate. While B3AR agonists may be used for the treatment of lower urinary tract symptoms in men with BPH if storage symptoms with standard BPH treatment are insufficient, B3AR agonists appear to have trivial or similar effects compared to current standard BPH treatment.

Keywords: Adrenergic beta-3 receptor agonists; Prostatic hyperplasia; Lower urinary tract symptoms

- Fund/Grant Support: This study was supported by Center of Evidence Based Medicine, Institute of Convergence Science, Yonsei University, Seoul, Korea.

- Conflict of Interest: SJK, a member of the Editorial Board of International Neurourology Journal, is the second author of this article. However, she played no role whatsoever in the editorial evaluation of this article or the decision to publish it. Except for that, no potential conflict of interest relevant to this article was reported.

Corresponding author: Jae Hung Jung (ib https://orcid.org/0000-0002-4990-7098 Department of Urology, Yonsei University Wonju College of Medicine, 20 Ilsanro, Wonju 26426, Korea

Email: geneuro95@yonsei.ac.kr

${ }^{*}$ Current affiliation: Department of Urology, Kangdong Sacred Heart Hospital,

Seoul, Korea

Submitted: February 19, 2021 / Accepted after revision: April 3, 2021 


\section{INTRODUCTION}

The prevalence of overactive bladder $(\mathrm{OAB})$ in women increases with age and is present in approximately $30 \%$ of women over the age of 65 , with an overall prevalence of $11.8 \%$ [1,2]. Traditional treatment modalities used for the management of $\mathrm{OAB}$ include behavioral therapy and pharmacological management. Anticholinergics (e.g., oxybutynin, propiverine, tolterodine, trospium, solifenacin, and darifenacin) have been the mainstay of pharmacologic management [3].

Since 1970, 3 subtypes of beta-adrenoreceptors (BARs) have been identified. Among them, B3AR, which is dominant in the lower urinary tract (including the bladder, prostate, and urethra) has become popular urological practice [4]. Detrusor relaxation is primarily mediated by the cyclic adenosine monophosphate pathway, which is activated by the binding of norepinephrine to B3AR [5]. Mirabegron, a B3AR agonist, was approved by the U.S. Food and Drug Administration and has been widely used for patients with $\mathrm{OAB}$ in clinical practice, while other candidates of B3AR agonists are currently being validated in phase II and III clinical trials [6-8]. Mirabegron, the first of a new class of oral compounds with a different mode of action from anticholinergics that showed clinical efficacy and safety compared to anticholinergics or placebo, has become the current standard of treatment for OAB in women [9].

Benign prostatic hyperplasia (BPH) is defined as an increased number of epithelial and stromal cells in the prostate gland that can cause lower urinary tract symptoms (LUTS). In particular, urinary urgency usually presets with characteristic symptoms and common comorbidities of OAB such as frequency and nocturia and may negatively impact public health and reduce quality of life (QoL) [10-12]. Alpha-blockers (ABs: alfuzosin, doxazosin, naftopidil, silodosin, tamsulosin, and terazosin) and 5-alpha-reductase inhibitors (dutasteride and finasteride) are standard treatments for men with LUTS secondary to $\mathrm{BPH}$ [13]. Current guidelines recommend B3AR agonists in men with moderate to severe LUTS who mainly struggle with bladder storage symptoms (e.g., urinary urgency, frequency, and nocturia) with standard treatment [14]. However, B3AR agonist which affects on beta 1 adrenoreceptor of human cardiovascular tissue has cardiovascular adverse events such as hypertension, tachycardia, and headache $[15,16]$.

However, it remains unclear whether the B3AR agonist has more clinical benefits and fewer adverse effects in men with $\mathrm{BPH}$ than in women. Therefore, we performed a systematic re- view to assess the effects of B3AR agonists in men with LUTS secondary to $\mathrm{BPH}$.

\section{MATERIALS AND METHODS}

This systematic review was based on published protocol (CRD 42021228988). We performed a comprehensive search using multiple databases, including the Cochrane Central Register of Controlled Trials in the Cochrane Library, MEDLINE, Embase, Scopus, Web of Science, Latin American and Caribbean Health Sciences Literature, and KoreaMed. We also searched for other resources such as ClinicalTrials.gov (www.clinicaltrials.gov/), the World Health Organization International Clinical Trials Registry Platform search portal (apps.who.int/trialsearch/), and Grey Literature Report (www.greylit.org/). The keywords and medical subject headings used for searching were "Prostatic Hyperplasia," "Prostatism," "Urinary Bladder Neck Obstruction," and "Adrenergic beta-3 Receptor Agonists." The search strategy for each database is presented in Supplementary Material 1. The date of the last search of all the databases was August 13, 2020. Two review authors (TWK, SJK, or JHJ) independently screened all potentially relevant records and classified the studies according to the criteria provided in the Cochrane Handbook for Systematic Reviews of Interventions [17]. All disagreements were resolved through discussion and consensus. We included randomized controlled trials (RCTs), regardless of publication status or language of publication. Adult men $\geq 40$ years of age with LUTS secondary to BPH (LUTS/BPH) were included. The age limitation was based on the observation that the prevalence of $\mathrm{BPH}$ increases in middle-aged and older men [18].

We excluded trials of men with a history of other causes of LUTS/BPH, such as known neurogenic bladder, bladder, and urethral anomalies, or surgeries for $\mathrm{BPH}$. We compared the B3AR agonist with other treatment modalities for LUTS/BPH, such as placebo, ABs, and anticholinergics. We only included the currently available B3AR agonist, mirabegron, in clinical practice. Concomitant interventions had to be the same in the experimental and comparator groups to establish fair comparisons. We focused on patient-important outcomes as a review outcome; therefore, urological symptom scores (e.g., International Prostate Symptom Scores [IPSS: total score ranges from 0 to 35 points, with higher scores indicating higher symptom severity], overactive bladder symptom score [OABSS: total score ranges from 0 to 15 points, with higher scores indicating higher 
symptom severity]), QoL (e.g., IPSS-QoL: scale of 0 to 6 [delighted to terrible]), adverse events, frequency of voiding, and acute urinary retention were considered as review outcomes. While we planned to perform meta-analyses for review outcomes, we were not able to perform these types of analyses primarily due to lack of data due to a small number of included studies and clinical heterogeneity. We also planned to use funnel plots to assess small study effects, however, the number of included studies was too low to generate funnel plot.

Two review authors (TWK, SJK, or JHJ) independently assessed the risk of bias of each included study on a per-outcome basis. All disagreements were resolved through discussion and consensus. We assessed the risk of bias using the Cochrane Risk of Bias assessment tool. We classified the risk of bias domains into "low risk," "high risk," or "unclear risk" and evaluated individual bias items as described in the Cochrane Handbook for Systematic Reviews of Interventions [17].

\section{RESULTS}

A comprehensive literature search identified 301 studies. After removal of duplicates, we screened the titles and abstracts of 271 records and excluded 261 studies. We screened 10 full-text articles and excluded 6 articles that did not meet the inclusion criteria or were not relevant to the question being investigated [12,19-23] (see Supplementary Material 2). Four studies ultimately met the inclusion criteria were included in the qualitative synthesis of this review [24-27]. The flow of literature through this assessment process is shown in the PRISMA (Preferred Reporting Items for Systematic Reviews and Meta-Analyses) flowchart (Fig. 1).

Table 1 shows baseline characteristics of the included studies. Three studies [24,26,27] were open-label studies, while one study [25] was double-blinded. The mean age of the men ranged from 64.9 to 75.9 years old. Mean baseline IPSS score ranged from 12.9 to 16.8 . The mean baseline prostate volume ranged from 30.5 to $41.4 \mathrm{~mL}$. The mean postvoid residual (PVR) was less than $50 \mathrm{~mL}$ in all included studies. All studies administered mirabegron as an oral agent (daily doses ranging from $25 \mathrm{mg}$ to $50 \mathrm{mg}$ ) and compared it to $\mathrm{ABs}$ (tamsulosin [daily doses from $0.2 \mathrm{mg}$ to $0.4 \mathrm{mg}$ ] and silodosin [daily dose of $8 \mathrm{mg}$ ]) [24-26], anticholinergics (fesoterodine [daily dose of 4 $\mathrm{mg}]$ ) [26], and phosphodiesterase 5 inhibitors (PDE5I, tadalafil [daily dose of $5 \mathrm{mg}$ ]) [27]. Only one study used placebo in control group [25]. All studies reported short-term outcome data ranging from 8 weeks to 12 weeks after treatment. While all studies have no conflicts of interest, 3 were supported by pharmaceutical companies $[24,25,27]$.

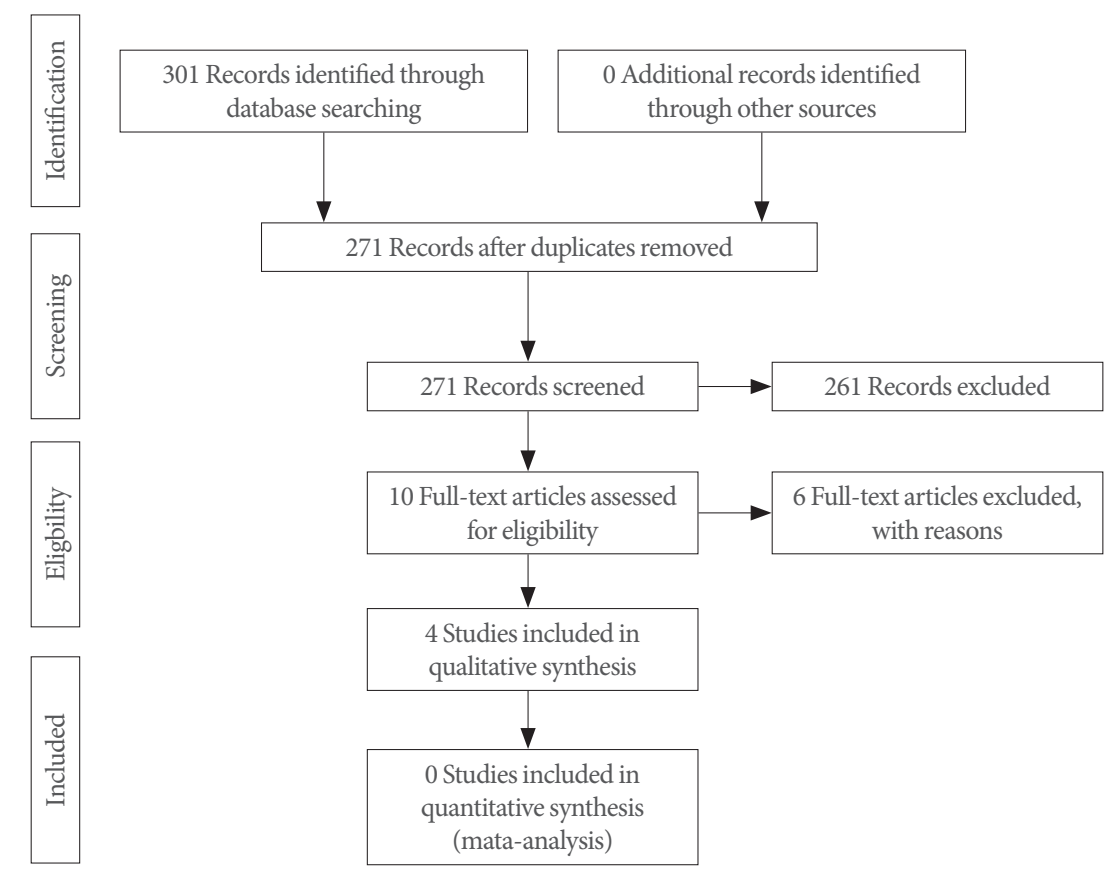

Fig. 1. Flow diagram. 


\section{Effect of the Intervention}

Table 2 shows the results of included studies.

\section{Combination therapy with $B 3 A R$ agonist and $A B$ versus $A B$ monotherapy}

Two RCTs with 809 randomized participants (combination, 403; monotherapy, 406) were included in the comparison $[24,25]$. Tamsulosin and mirabegron were administrated orally in 2 included studies as a treatment modality.

Compared to $\mathrm{AB}$ monotherapy, $\mathrm{B} 3 \mathrm{AR}$ agonist combination therapy with $\mathrm{AB}$ may result in little to no difference in urological symptom scores based on IPSS (mean difference [MD], -0.16 ; $95 \%$ confidence interval [CI], -0.98 to $0.66 ; 2$ studies; 747 participants; $\mathrm{I}^{2}=0 \%$ ) and OABSS (MD, $-0.87 ; 95 \% \mathrm{CI},-2.14$ to $0.40 ; 1$ study; 76 participants). While combination therapy may reduce frequency of voiding ( $\mathrm{MD},-0.39 .95 \% \mathrm{CI},-0.76$ to -0.02 ; 1 study; 776 participants), combination therapy has similar ef- fects on QoL (MD, - $0.07 ; 95 \%$ CI, -0.68 to $0.54 ; 1$ study; 76 participants), adverse events (risk ratio [RR], 2.10; $95 \%$ CI, 0.17 to 26.16; 2 studies; 787 participants; $\mathrm{I}^{2}=71 \%$ ), and acute urinary retention (RR, 4.69; 95\% CI, 0.81 to 27.21; 2 studies; 787 participants; $\mathrm{I}^{2}=0 \%$ ). Contrast to Ichihara et al. [24], Kaplan et al. [25] reported higher rates of adverse events in $\mathrm{AB}$ monotherapy group compared to combination therapy group although drug adverse events was higher in combination therapy group (RR, 2.01 ; $95 \%$ CI, 1.22 to 3.32 ).

\section{Combination therapy with $B 3 A R$ agonist and $A B$ versus combi- nation therapy with anticholinergic and $A B$}

According to a study with 120 randomized participants (B3AR agonist combination: 60 , anticholinergic combination: 60 ) comparing the combination therapy of mirabegron and silodosin to combination therapy of fesoterodine and silodosin in patients with $\mathrm{BPH}$ [26], B3AR agonist combination therapy

Table 1. Baseline characteristics of included studies

\begin{tabular}{|c|c|c|c|c|c|}
\hline \multirow[b]{2}{*}{ Study } & \multirow[b]{2}{*}{$\begin{array}{l}\text { Study design/setting/ } \\
\text { country }\end{array}$} & \multicolumn{4}{|c|}{ Population } \\
\hline & & Inclusion criteria & $\begin{array}{c}\text { No of randomized } \\
\text { participants } \\
\text { (intervention/ } \\
\text { comparator) }\end{array}$ & $\begin{array}{l}\text { Age (intervention/ } \\
\text { comparator) (yr), } \\
\text { mean } \pm \mathrm{SD}\end{array}$ & $\begin{array}{c}\text { Prostate volume } \\
\text { (intervention/ } \\
\text { comparator) }(\mathrm{mL}) \text {, } \\
\text { mean } \pm \mathrm{SD}\end{array}$ \\
\hline $\begin{array}{l}\text { Ichihara et al. } \\
\text { [24] } 2015\end{array}$ & $\begin{array}{l}\text { RCT: open label/ } \\
\text { multicenter/Japan }\end{array}$ & $\begin{array}{l}\text { Men aged } 50 \text { or older with LUTS most } \\
\text { likely secondary to BPO }\end{array}$ & $94(47 / 47)$ & $\begin{array}{l}75.9 \pm 7.5 / \\
73.1 \pm 8.7\end{array}$ & $\begin{array}{l}36.5 \pm 16.5 / \\
31.9 \pm 15.7\end{array}$ \\
\hline $\begin{array}{l}\text { Kaplan et al. } \\
\text { [25] } 2020\end{array}$ & $\begin{array}{l}\text { RCT: double blinded } \\
\text { phase IV/ multicenter/ } \\
\text { North America and } \\
\text { Europe }\end{array}$ & $\begin{array}{l}\text { Men aged } 40 \text { or older who had been } \\
\text { receiving } 0.4 \text { mg tamsulosin daily for } 2 \\
\text { or more months for the treatment of } \\
\text { previously diagnosed BPH associated } \\
\text { LUTS based on the clinical judgment of } \\
\text { the investigator, had symptoms of OAB } \\
\text { (8 or more micturitions per day and } 2 \\
\text { or more urgency episodes per day), and } \\
\text { had a PSA less than } 4 \text { ng/mL or } 4 \text { to less } \\
\text { than } 10 \mathrm{ng} / \mathrm{mL} \text { with a negative biopsy } \\
\text { within } 2 \text { years }\end{array}$ & $715(356 / 359)$ & $\begin{array}{l}64.9 \pm 8.4 / \\
64.9 \pm 9.6\end{array}$ & NR \\
\hline $\begin{array}{l}\text { Matsukawa et al. } \\
\text { [26] } 2019\end{array}$ & $\begin{array}{l}\text { RCT: open label/single } \\
\text { center/Japan }\end{array}$ & $\begin{array}{l}\text { Men aged } 50 \text { or older; IPSS } \geq 8 \text {; IPSS- } \\
\text { quality of life } \geq 3 \text {; total OABSS } \geq 3 \text {; one } \\
\text { or more urinary urgency episodes per } \\
\text { week; prostate volume } \geq 25 \mathrm{~mL} \text {; } \\
\text { maximum urinary flow rate }<15 \mathrm{~mL} \text { / } \\
\text { sec at a voided volume of } \geq 100 \mathrm{~mL} \text {; } \\
\text { and residual urine }<150 \mathrm{~mL}\end{array}$ & $120(60 / 60)$ & $\begin{array}{l}71.5 \pm 8.4 / \\
72.4 \pm 8.2\end{array}$ & $\begin{array}{l}41.4 \pm 16.4 / \\
40.1 \pm 15.1\end{array}$ \\
\hline $\begin{array}{l}\text { Yamanishi et al. } \\
\text { [27] } 2020\end{array}$ & $\begin{array}{l}\text { RCT: open label/single } \\
\text { center/Japan }\end{array}$ & $\begin{array}{l}\text { Men aged from } 50 \text { to } 89 \text { years with LUTS } \\
\text { (In protocol, patients with } \mathrm{BPH} \text { ) }\end{array}$ & $176(89 / 87)$ & $\begin{array}{l}72.4 \pm 7.4 / \\
72.3 \pm 8.0\end{array}$ & $\begin{array}{l}32.1 \pm 13.1 / \\
30.5 \pm 12.8\end{array}$ \\
\hline
\end{tabular}

IPSS, International Prostate Symptom Score; SD, standard deviation; RCT, randomized controlled trial; LUTS, lower urinary tract symptoms; BPO, benign prostatic obstruction; $\mathrm{BPH}$, benign prostatic hyperplasia; OAB, Overactive Bladder; PSA, prostate specific antigen; NR, not reported.

(Contined to the next page) 
Table 1. Continued

\begin{tabular}{|c|c|c|c|c|c|}
\hline \multirow[b]{2}{*}{ Study } & \multirow[b]{2}{*}{ Intervention } & \multirow[b]{2}{*}{ Comparator } & \multicolumn{2}{|r|}{ Outcomes } & \multirow{2}{*}{$\begin{array}{l}\text { Study duration } \\
\text { (run-in period) }\end{array}$} \\
\hline & & & $\begin{array}{l}\text { Primary } \\
\text { outcomes }\end{array}$ & $\begin{array}{l}\text { Secondary } \\
\text { outcomes }\end{array}$ & \\
\hline $\begin{array}{l}\text { Ichihara et al. } \\
\text { [24] } 2015\end{array}$ & $\begin{array}{r}\text { Mirabegron }(50 \mathrm{mg} / \text { day })+ \\
\text { tamsulosin }(0.4 \mathrm{mg} / \text { day })\end{array}$ & $\begin{array}{l}\text { Tamsulosin } \\
(0.2 \mathrm{mg} / \text { day })\end{array}$ & OABSS & $\begin{array}{l}\text { IPSS } \\
\text { Quality of life } \\
\text { Qmax }\end{array}$ & $\begin{array}{l}8 \text { Weeks (at least } 8 \text { weeks } \\
\text { tamsulosin } 0.2 \mathrm{mg} / \text { day) }\end{array}$ \\
\hline $\begin{array}{c}\text { Kaplan et al. } \\
\text { [25] } 2020\end{array}$ & $\begin{array}{l}\text { Mirabegron }(25 \mathrm{mg} / \text { day } \\
\text { for } 4 \text { weeks, and titrated } \\
\text { to } 50 \mathrm{mg} / \text { day for } 8 \\
\text { weeks })+ \text { tamsulosin } \\
(0.4 \mathrm{mg} / \text { day })\end{array}$ & $\begin{array}{l}\text { Placebo + } \\
\text { tamsulosin } \\
(0.4 \mathrm{mg} / \text { day })\end{array}$ & $\begin{array}{l}\text { No. of micturitions } \\
\text { per day }\end{array}$ & $\begin{array}{l}\text { Mean volume voided per micturi- } \\
\text { tion } \\
\text { No. of urgency episodes per day } \\
\text { (grade } 3 / 4 \text { ) } \\
\text { Total urgency and frequency Score } \\
\text { IPSS } \\
\text { No. of incontinence episodes per } \\
\text { day } \\
\text { OAB-q symptom bother score } \\
\text { Patient perception of bladder } \\
\text { condition }\end{array}$ & $\begin{array}{l}12 \text { Weeks ( } 4 \text { weeks } \\
\text { tamsulosin } 0.4 \mathrm{mg} / \text { day) }\end{array}$ \\
\hline $\begin{array}{l}\text { Matsukawa et al. } \\
\text { [26] } 2019\end{array}$ & $\begin{array}{l}\text { Mirabegron (50 mg/day) } \\
\text { + silodosin ( } 8 \mathrm{mg} / \text { day })\end{array}$ & $\begin{array}{l}\text { Fesoterodine } 4 \mathrm{mg} / \\
\text { day }+ \text { silodosin } 8 \\
\text { mg/day }\end{array}$ & OABSS & $\begin{array}{l}\text { Subjective symptoms (IPSS, quality } \\
\text { of life) } \\
\text { Objective findings (bladder volume, } \\
\text { detrusor overactivity, Qmax, PVR, } \\
\text { detrusor pressure at Qmax, } \\
\text { bladder contractility index, } \\
\text { bladder outlet obstruction index) }\end{array}$ & $\begin{array}{l}12 \text { Weeks (12-24 weeks } \\
\text { silodosin } 8 \mathrm{mg} \text { /day) }\end{array}$ \\
\hline $\begin{array}{l}\text { Yamanishi et al. } \\
\text { [27] } 2020\end{array}$ & $\begin{array}{l}\text { Mirabegron (50 mg/day) } \\
+ \text { tadalafil ( } 5 \mathrm{mg} / \text { day })\end{array}$ & $\begin{array}{l}\text { Tadalafil } \\
\text { (5 mg/day) }\end{array}$ & OABSS & $\begin{array}{l}\text { OABSS subscore } \\
\text { IPSS } \\
\text { NIH-CPSI } \\
\text { Micturition chart variables (number } \\
\text { of voids, number of nighttime } \\
\text { voids, number of urgency } \\
\text { episodes, number of urgency } \\
\text { incontinence episodes) } \\
\text { Uroflowmetry parameters (voided } \\
\text { volume, Qmax, Qave, PVR, } \\
\text { bladder voiding efficiency) }\end{array}$ & $\begin{array}{l}12 \text { Weeks (at least } 8 \text { weeks } \\
\text { tadalafil } 5 \mathrm{mg} / \text { day) }\end{array}$ \\
\hline
\end{tabular}

OABSS, overactive bladder symptom score; IPSS, International Prostate Symptom Score; OAB-q, overactive bladder questionnaire; Qave, average flow rate; PVR, postvoid residual urine volume; Qmax, maximum flow rate; NIH-CPSI, National Institutes of Health Chronic Prostatitis Symptom Index.

showed a little to no difference in urological symptom scores based on IPSS (MD, 0.30; 95\% CI, -1.27 to 1.87 ; 102 participants) and OABSS (MD, 1.30; 95\% CI, 0.47 to 2.13; 102 participants). QoL was similar between the 2 groups (MD, 0.40; $95 \%$ CI, -0.01 to $0.81 ; 102$ participants). Both treatment modalities have similar effect on adverse event (RR, 0.52; 95\% CI, 0.21 to $1.31 ; 102$ participants). In addition, there was no acute urinary retention in either group. The study did not report the frequency of voiding outcome.

\section{Combination therapy with B3AR agonist and PDE5I versus PDE5I monotherapy}

We found one RCT with 176 randomized participants (B3AR agonist combination: 89 , PDE5I monotherapy: 87 ) to evaluate the efficacy and safety of combination therapy with mirabegron and tadalafil compared to tadalafil monotherapy in patients with $\mathrm{BPH}$ [27]. Combination therapy with B3AR agonist with PDE5I may improve urological symptom scores based on IPSS (MD, -1.86 ; 95\% CI, -3.27 to $-0.45 ; 161$ participants) and OABSS compared to PDE5I monotherapy (MD, -1.85; 95\% CI, 


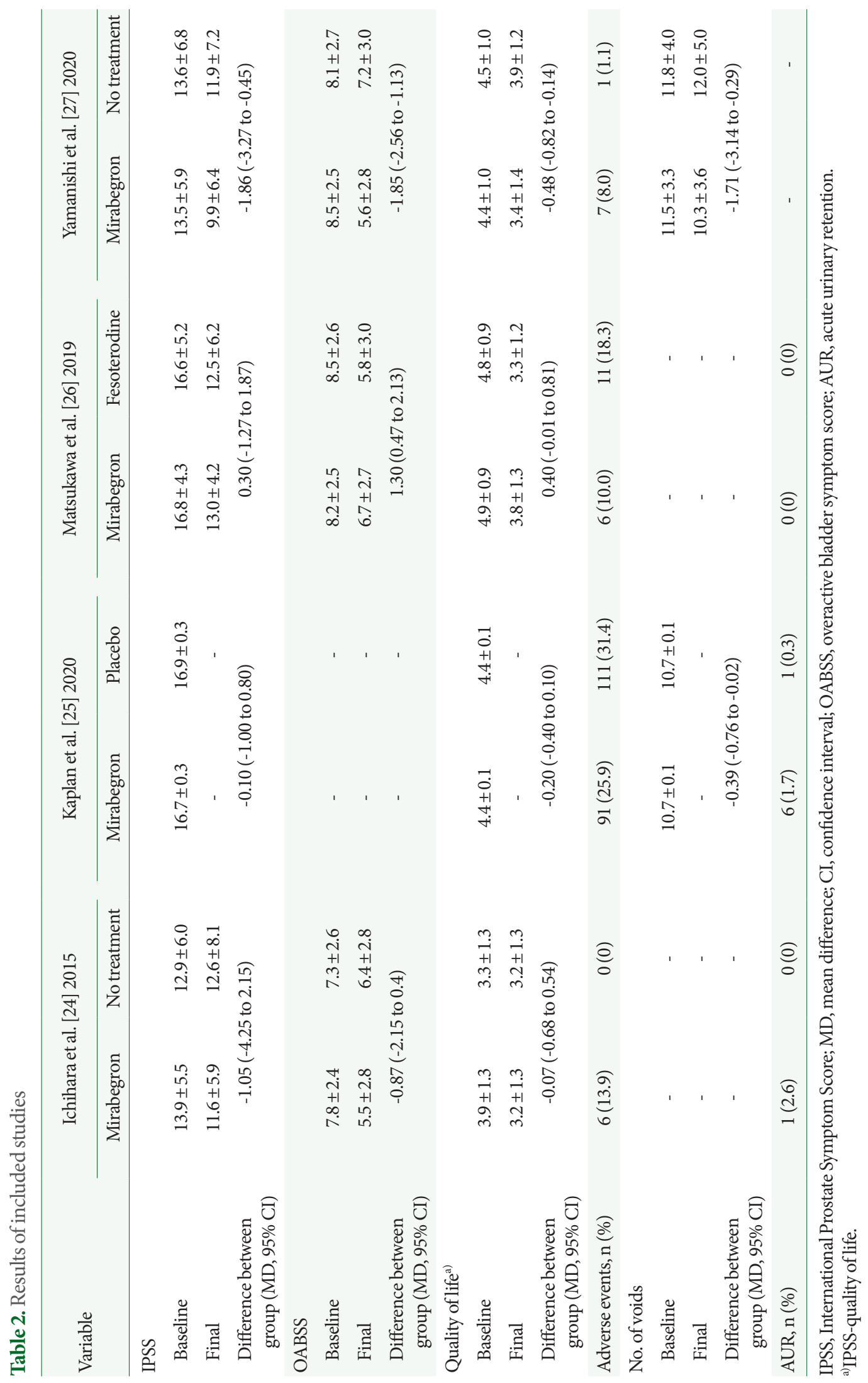




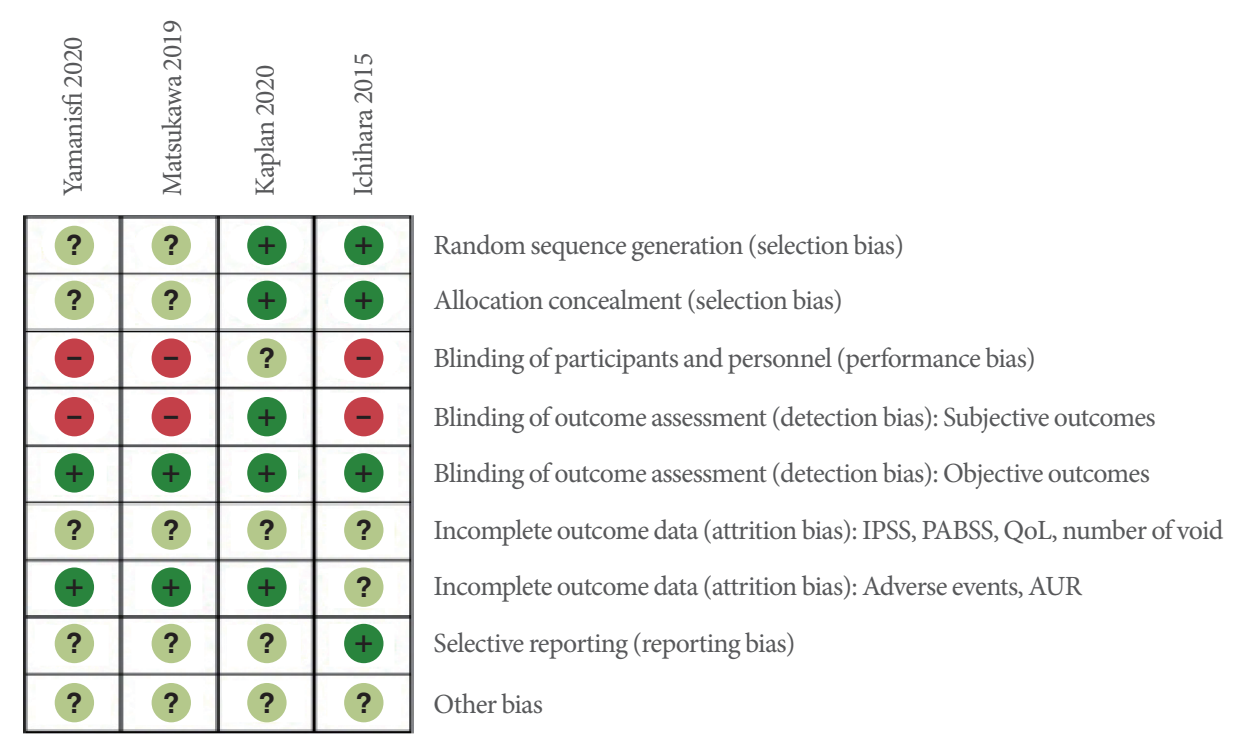

Fig. 2. Risk of bias: review authors' judgements about each risk of bias item for each included study. Subjective outcomes: IPSS, OABSS, QoL, number of voids. Objective outcomes: adverse events, AUR. AUR, acute urinary retention; IPSS, International Prostate Symptom Score; OABSS, overactive bladder symptom score; QoL, quality of life.

-2.56 to $-1.13 ; 161$ participants). In addition, combination therapy with B3AR agonist with PDE5I also may improve QoL (MD, $-0.48 ; 95 \% \mathrm{CI},-0.82$ to $-0.14 ; 161$ participants). While there was similar effect on adverse events (RR, $6.91 ; 95 \% \mathrm{CI}$, 0.87 to $54.92 ; 161$ participants), combination therapy appears to reduce the frequency of micturition (MD, $-1.71 ; 95 \% \mathrm{CI},-3.14$ to $-0.29 ; 150$ participants). There was no acute urinary retention in either group.

\section{Risk of Bias}

Fig. 2 shows a summary of risk of bias assessment.

Sequence generation for participation allocation was adequate in 2 studies, with both rated at a low risk of bias [24,25]. In the remaining trials, the method of sequence generation was unclear or not specified. Two trials had adequate allocation concealment (e.g., central registration using an allocation table) and were at low risk of bias [24,25]. In the remaining trials, treatment allocation was unclear. All studies had an unclear or high risk of performance bias. While all studies were judged as having a low risk of detection bias with regard to objective outcomes such as adverse events and acute urinary retention, 3 studies were at high risk of bias for subjective outcomes such as urological symptom scores, QoL, and number of voids [24, 26,27]. The risk of attrition bias (incomplete outcome data) with regard to subjective outcomes was unclear in all of the studies; only one had an unclear risk of attrition bias for objec- tive outcomes [24]. The remaining patients were deemed to have a low risk of attrition bias [25-27]. Although the protocols of all included studies were registered a priori, we reclassified 3 studies to be at a high risk of bias due to important deficits in outcome reporting [25-27]. All of the studies were at an unclear risk of bias due to the inclusion of participants who did not respond to standard treatment.

\section{DISCUSSION}

Despite the similar prevalence of OAB symptoms in men and women, oral pharmacologic regimens for male $\mathrm{OAB}$ have been used less frequently in men because of the difference in symptom characteristics between men (e.g., mainly storage symptoms such as frequency, urgency, and nocturia) and women (e.g., incontinence including stress and mixed incontinence) [28]. Additionally, men with $\mathrm{BPH}$ often receive $\mathrm{ABs}$ as a firstline treatment option, but storage LUTS remain bothersome in two-thirds of such men.

However, a multicenter phase II study that featured 200 men aged over 45 years with LUTS and bladder outlet obstruction for 12 weeks reported that the B3AR agonist significantly reduced micturition frequency and urgency episodes compared to placebo without impairment of urodynamic parameters (such as detrusor pressure at maximal flow rate) [29]. In 2017, post hoc analysis using 5 phase III studies with a total of 1,187 
male participants (around $20 \%$ of the total study population) to determine the efficacy and safety of mirabegron in male patients with $\mathrm{OAB}$ indicated that mirabegron demonstrated superiority in the reduction of micturition frequency $(\mathrm{MD},-0.37$; $95 \%$ CI, -0.74 to -0.01) compared to placebo; improvements in urgency, frequency, and incontinence were also seen, exhibiting similar characteristics as anticholinergics (tolterodine or solifenacin). With regard to treatment-related adverse events, the overall incidence rate of mirabegron was similar to placebo and anticholinergics. In addition, the incidence rate of hypertension, the most frequent cardiovascular adverse events, was similar for mirabegron, anticholinergic, and placebo groups. Interestingly, they reported no remarkable changes in PVR with the use of mirabegron or placebo in patients with or without a history of LUTS associated with BPH (they only reported this outcome according to the presence of BPH in men) [12]. As an additional therapeutic option in men with $\mathrm{OAB}$ symptoms who were being treated with $\mathrm{ABs}$, a 4-week mirabegron treatment period resulted in an improvement in IPSS and QoL [30,31].

The finding of our review, however, are not consistent with those of previous report of $\mathrm{OAB}$ patients. While B3AR agonist can improve the patient-important outcomes within group (before and after treatment), it does not appear to have additional effects on urological symptom scores and QoL compared to current standard $\mathrm{BPH}$ treatment such as $\mathrm{AB}$ or anticholinergic. Although B3AR agonist therapy with PDE5I showed statistical improvement on urological symptom scores or QoL compared to PDE5I monotherapy, it must be due to the difference of pharmacologic profile. B3AR agonist may reduce frequency of voiding compared to $\mathrm{AB}$ or PDE5I monotherapy, but the effect estimates may be clinically trivial. For safety profile, B3AR agonist does not appear to increase adverse event rate as well as acute urinary retention rate. However, one RCT compared $\mathrm{B} 3 \mathrm{AR}$ agonist combination therapy with $\mathrm{AB}$ to $\mathrm{AB}$ monotherapy reported 3 serious cardiovascular adverse events (1 acute myocardial infarction, 1 angina pectoris, 1 cerebral infarction). Although post hoc analysis reported the effects of mirabegron in men with $\mathrm{OAB}$ (not only in men with $\mathrm{BPH}$ ), we believe that our review is the most recent evidence for the use of B3AR agonists in men with BPH. The major limitation of current evidence for B3AR agonists is the heterogeneous definition of $\mathrm{BPH}$ among the included studies. For example, Yamanishi et al. [27] included men aged 50-89 years with LUTS. Therefore, a proportion of included participants may not have been patients with $\mathrm{BPH}$, even if their mean prostatic volume was over $30 \mathrm{~mL}$.
Additionally, further studies are needed to provide assurance of long-term effectiveness and safety of beta 3 agonists as the elderly are more likely to take the B3AR agonist as a combination therapy with conventional $\mathrm{BPH}$ in clinical practice. As most studies in this review only included Asian men, there are also limitations in generalizing the results. Almost all studies were sponsored by pharmaceutic companies, raising concerns about conflicts of interest and publication bias that can overestimate the effect size. Even though the authors performed a comprehensive search without any publication or language restrictions, it is possible that additional studies may have been conducted but not yet published. Particularly, some negative studies may have been published in unindexed journals or only presented at local conferences, which can deviate from our search and lead to potential publication biases. Finally, only 1 study was doubleblinded, while the others were open-blinded. There is a consistent need for greater methodological rigor and transparency reporting.

There was uncertainty in body of evidence of B3AR agonists for the treatment of LUTS in men with BPH. In conclusion, clinical guidelines recommended that B3AR agonists may be used for the treatment of LUTS in men with BPH if storage symptoms with standard BPH treatment are insufficient. However, clinicians should keep in mind that adding B3AR agonists appear to have trivial or similar effects compared to current standard BPH treatment.

\section{SUPPLEMENTARY MATERIALS}

Supplementary materials can be found via https://doi.org/10. 5213/inj.2142068034.

\section{AUTHOR CONTRIBUTION STATEMENT}

- Conceptualization: $J H J$

- Data curation: TWK, MHK

- Formal analysis: $S J K, M H K, J H J$

- Methodology: SJK, JHJ

- Project administration: SJK

-Writing-original draft: TWK

· Writing-review \& editing: JHJ

\section{ORCID}

Tae Wook Kang

0000-0003-4236-0664 
Su Jin Kim

0000-0002-1917-2780

Myung Ha Kim

0000-0002-7899-3407

Jae Hung Jung

0000-0002-4990-7098

\section{REFERENCES}

1. Irwin DE, Milsom I, Hunskaar S, Reilly K, Kopp Z, Herschorn S, et al. Population-based survey of urinary incontinence, overactive bladder, and other lower urinary tract symptoms in five countries: results of the EPIC study. Eur Urol 2006;50:1306-14; discussion 145.

2. Stewart WF, Van Rooyen JB, Cundiff GW, Abrams P, Herzog AR, Corey R, et al. Prevalence and burden of overactive bladder in the United States. World J Urol 2003;20:327-36.

3. Srikrishna S, Robinson D, Cardozo L, Vella M. Management of overactive bladder syndrome. Postgrad Med J 2007;83:481-6.

4. Schena G, Caplan MJ. Everything you always wanted to know about $\beta(3)-\mathrm{AR}^{*}$ ( ${ }^{\star}$ but were afraid to ask). Cells 2019;8:357.

5. Yamaguchi O. Beta3-adrenoceptors in human detrusor muscle. Urology 2002;59:25-9.

6. Gormley EA, Lightner DJ, Faraday M, Vasavada SP. Diagnosis and treatment of overactive bladder (non-neurogenic) in adults: AUA/ SUFU guideline amendment. J Urol 2015;193:1572-80.

7. Gratzke C, Bachmann A, Descazeaud A, Drake MJ, Madersbacher $\mathrm{S}$, Mamoulakis $\mathrm{C}$, et al. EAU guidelines on the assessment of nonneurogenic male lower urinary tract symptoms including benign prostatic obstruction. Eur Urol 2015;67:1099-109.

8. Yoshida M, Takeda M, Gotoh M, Nagai S, Kurose T. Vibegron, a novel potent and selective $\beta(3)$-adrenoreceptor agonist, for the treatment of patients with overactive bladder: a randomized, double-blind, placebo-controlled phase 3 study. Eur Urol 2018;73:78390.

9. Athanasopoulos A, Giannitsas K. An overview of the clinical use of antimuscarinics in the treatment of overactive bladder. Adv Urol 2011;2011:820816.

10. Barry MJ, Williford WO, Chang Y, Machi M, Jones KM, WalkerCorkery E, et al. Benign prostatic hyperplasia specific health status measures in clinical research: how much change in the American Urological Association symptom index and the benign prostatic hyperplasia impact index is perceptible to patients? J Urol 1995; 154:1770-4.

11. Roehrborn CG. Pathology of benign prostatic hyperplasia. Int J Impot Res 2008;20 Suppl 3:S11-8.

12. Tubaro A, Batista JE, Nitti VW, Herschorn S, Chapple CR, Blauwet $\mathrm{MB}$, et al. Efficacy and safety of daily mirabegron $50 \mathrm{mg}$ in male patients with overactive bladder: a critical analysis of five phase III studies. Ther Adv Urol 2017;9:137-54.

13. Lepor H, Williford WO, Barry MJ, Brawer MK, Dixon CM, Gormley $\mathrm{G}$, et al. The efficacy of terazosin, finasteride, or both in benign prostatic hyperplasia. Veterans Affairs Cooperative Studies Benign Prostatic Hyperplasia Study Group. N Engl J Med 1996;335:533-9.

14. Gravas S, Cornu JN, Gacci M, Gratzke C, Herrmann TRW, Mamoulakis $\mathrm{C}$, et al. EAU guidelines on management of non-neurogenic male lower urinary tract symptoms (LUTS), incl. benign prostatic obstruction (BPO) 2020. European Association of Urology Guidelines. 2020 Edition. Arnhem (The Netherlands): European Association of Urology Guidelines Office; 2020.

15. Mo W, Michel MC, Lee XW, Kaumann AJ, Molenaar P. The $\beta(3)$ -adrenoceptor agonist mirabegron increases human atrial force through $\beta(1)$-adrenoceptors: an indirect mechanism? Br J Pharmacol 2017;174:2706-15.

16. Bragg R, Hebel D, Vouri SM, Pitlick JM. Mirabegron: a beta-3 agonist for overactive bladder. Consult Pharm 2014;29:823-37.

17. Higgins JP, Altman DG, Gøtzsche PC, Jüni P, Moher D, Oxman $\mathrm{AD}$, et al. The Cochrane Collaboration's tool for assessing risk of bias in randomised trials. BMJ 2011;343:d5928.

18. Egan KB. The epidemiology of benign prostatic hyperplasia associated with lower urinary tract symptoms: prevalence and incident rates. Urol Clin North Am 2016;43:289-97.

19. Kakizaki H, Lee KS, Yamamoto O, Jong JJ, Katou D, Sumarsono B, et al. Mirabegron add-on therapy to tamsulosin for the treatment of overactive bladder in men with lower urinary tract symptoms: a randomized, placebo-controlled study (MATCH). Eur Urol Focus 2020;6:729-37.

20. World Health Organization (WHO). Comparison of mirabegron versus tamsulosin patients of benign prostate enlargement with overactive bladdder symptoms [Internet]. Geneva (Switzerland): WHO; 2018 [cited 2020 Aug 26]. Available from: http://www.who. int/trialsearch/Trial2.aspx?TrialID=CTRI/2018/12/016541.

21. Matsukawa Y, Gotoh M. Factors contributing to the efficacy of two add-on therapies of fesoterodine or mirabegron to silodosin monotherapy for persistent overactive bladder in men with lower urinary tract symptoms. Int J Urol 2020;27:85-6.

22. Nitti V, Rosenberg S, Mitcheson HD, He W, Fakhoury A, Martin N. 1869 Randomized, multicenter phase II study evaluating the urodynamic safety of mirabegron in males with lower urinary tract symptoms (LUTS) and bladder outlet obstruction (BOO). J Urol 2012;187:e756.

23. Nitti VW, Auerbach S, Martin N, Calhoun A, Lee M, Herschorn S. Results of a randomized phase III trial of mirabegron in patients 
with overactive bladder. J Urol 2013;189:1388-95.

24. Ichihara K, Masumori N, Fukuta F, Tsukamoto T, Iwasawa A, Tanaka Y. A randomized controlled study of the efficacy of tamsulosin monotherapy and its combination with mirabegron for overactive bladder induced by benign prostatic obstruction. J Urol 2015;193:921-6.

25. Kaplan SA, Herschorn S, McVary KT, Staskin D, Chapple C, Foley S, et al. Efficacy and safety of mirabegron versus placebo add-on therapy in men with overactive bladder symptoms receiving tamsulosin for underlying benign prostatic hyperplasia: a randomized, phase 4 study (PLUS). J Urol 2020;203:1163-71.

26. Matsukawa Y, Takai S, Majima T, Funahashi Y, Sassa N, Kato M, et al. Comparison in the efficacy of fesoterodine or mirabegron addon therapy to silodosin for patients with benign prostatic hyperplasia complicated by overactive bladder: a randomized, prospective trial using urodynamic studies. Neurourol Urodyn 2019;38:941-9.

27. Yamanishi T, Kaga K, Sakata K, Yokoyama T, Kageyama S, Fuse M, et al. A randomized controlled study of the efficacy of tadalafil monotherapy versus combination of tadalafil and mirabegron for the treatment of persistent overactive bladder symptoms in men presenting with lower urinary tract symptoms (CONTACT Study). Neurourol Urodyn 2020;39:804-12.

28. Agarwal A, Eryuzlu LN, Cartwright R, Thorlund K, Tammela TL, Guyatt $\mathrm{GH}$, et al. What is the most bothersome lower urinary tract symptom? Individual- and population-level perspectives for both men and women. Eur Urol 2014;65:1211-7.

29. Nitti VW, Rosenberg S, Mitcheson DH, He W, Fakhoury A, Martin NE. Urodynamics and safety of the $\beta 3$-adrenoceptor agonist mirabegron in males with lower urinary tract symptoms and bladder outlet obstruction. J Urol 2013;190:1320-7.

30. Ogura K, Sengiku A, Miyazaki Y, Sawazaki H, Takahashi T. 1091 Effects of add-on mirabegron on storage symptoms in men with lower urinary tract symptoms receiving alpha-1 blocker therapy. Eur Urol Suppl 2013;12:e1091.

31. Kang TW, Chung HC. Add-on treatment with mirabegron may improve quality of life in patients with benign prostatic hyperplasia complaining of persistent storage symptoms after tamsulosin monotherapy. Ther Adv Urol 2020;12:1756287220974130. 